\title{
Polyneuropathy in patients undergoing cardiac surgery
}

\begin{abstract}
In recent years the complexity of the cardio-surgical interventions has increased significantly. The number of the patients with the severe comorbidity background that are being operated is constantly increasing. ${ }^{1}$ Nowadays the frequency of the complications after cardiopulmonary bypass surgery is still rather high $-20-30 \%{ }^{2}$ One of the complications that is appeared in patients undergoing cardio-surgical interventions is a polyneuropathy.
\end{abstract}

Keywords: cardiac surgery, polyneuropathy, EMG, multiple organ failure, sepsis
Volume 9 Issue 2 - 2017

\author{
Davidov NR, Vinogradov OI, Gorokhovatskiy \\ YI, Kuznetsov AN \\ National Pirogov Centre of Therapy and Surgery, National \\ Center of Cerebrovascular Disorders, Russia
}

\begin{abstract}
Correspondence: Davidov NR, National Pirogov Centre of Therapy and Surgery, National Center of Cerebrovascular Disorders, Moscow, Russia, Email dr.d.natan@mail.ru
\end{abstract}

Received: November 12, 2017 | Published: November 17. 2017
The aim of the research was to determine the cause of polyneuropathy in patients undergone heart surgery.

\section{Material and methods}

Sixty patients (36 - male, 24 - female) undergone cardiopulmonary bypass surgery were examined. The cohort was divided into two groups. Twenty patients (9 - male, 11 - female) who debuted polyneuropathy in early postoperative period after the heart surgery were included in the $1^{\text {st }}$ (main) group. The patients of the 2 nd control group $(n=40)$ had also been undergone cardio-surgical interventions, but had no signs of polyneuropathy in early postoperative period.

The following cardiac surgeries were performed to all the patients: coronary artery bypass surgery in $51,7 \%$ of cases, reconstructive surgery on heart valves in $48,3 \%$ of cases. The patients of the both groups had comparable characteristics of age and sex. Preoperative, intraoperative and postoperative prospective factors that might cause the development of polyneuropathy were assessed in all the patients.

\section{Results}

Degree of incidence of the prospective factors, contributed to the development of polyneuropathy in preoperative and intraoperative periods in patients of both groups didn't differ significantly, $(p>0,05)$. Signs of polyneuropathy were revealed in 20 patients in postoperative period. These patients made up the main group ( 9 men, 11 women). The control group of 40 people ( 27 men, 13 women) was composed by the patients who had also undergone the cardio-surgical interventions, but had no signs of polyneuropathy in postoperative period. Preoperative rates as well as intraoperative rates in patients of both groups didn't differ significantly.

Multiple organ failure syndrome $(p<0,01)$, sepsis $(p<0,01)$, pneumonia $(p<0,01)$, myocardial infarction $(p<0,05)$, pleurisy $(p<0,05)$ were presented in patients of the main group in postoperative period significantly more often. Multiple organ failure was diagnosed in 19 patients of the main group and 1 patient of the control group, sepsis - 20 patients and 1 patient respectively, pneumonia - 17 in the main group and 4 of the control, 5 patients of the main group and 2 of the control one had myocardial infraction, pleurisy was in 7 and 5 patients respectively. Patients of the main group were treated in an intensive care unit significantly more often 19,4 bed-day, the control group - 1,5 bed-day $(\mathrm{p}<0,01)$; had the artificial lung ventilation for a longer period - 15,1 bed-day, the control group - 0,4 bed-day $(p<0,01)$; they were provided by a longer inotropic support 12,3 bed-day, the control group - 0,4 bed-day $(\mathrm{p}<0,01)$ and a drug sedation comparing to the patients of the control group 10,5 bed-day and 0,4 bed-day respectively $(p<0,01)$. Most frequently antibiotic therapy received by the patients of the main group than the control: $20(100 \%)$ and 9 $(22,5 \%), \mathrm{p}<0.01$.

\section{Discussion}

The etiology of polyneuropathy in patients undergoing cardiac surgeries is still inadequately explored and in every specific case oftentimes remains unexplained. From the perspective of our research in 20 patients out of 60 after cardiac surgery polyneuropathy signs were revealed according to clinical pattern and EMG results. There is no data of possible preoperative or intraoperative predictors of polyneuropathy development in patients undergone cardiac surgeries in available contemporary literature. Our research also hasn't shown any significant preoperative or intraoperative risk factors of polyneuropathy development in postoperative period.

We tested the possible polyneuropathy development risk factors in postoperative period in patients undergone cardio-surgical interventions. According to the research of Thiele RI et al. ${ }^{3}$ the authors came to the conclusion that sepsis, the increased level of urea and using of high doses of catecholamines may cause polyneuropathy in patients undergone cardiac surgeries. ${ }^{3}$ Chen $\mathrm{HC}$ et al. ${ }^{4}$ suggested that any kind of muscle weakness, limb paralysis as well as difficult weaning from artificial lung ventilation developed in patients with inflammatory response syndrome after cardiac surgeries were the signs of polyneuropathy. The polyneuropathy itself is considered to be the complication of the systemic inflammatory response and sepsis. ${ }^{4}$

The results of our research have shown that the development of polyneuropathy in postoperative period in patients undergone cardiac surgeries is associated with sepsis and multiple organ failure that are corresponding to the literature data. These patients need to stay in an intensive care unit for longer time, they need prolonged inotropic support, drug sedation, artificial lung ventilation as well as a long lasting antibiotic therapy. Lots of mechanisms have been proposed to explain the pathophysiology of polyneuropathy in critically ill 
patients, the majority of which are complicated and aren't fully clear or well proven. ${ }^{5}$

A number of studies ${ }^{6-8}$ have shown that polyneuropathy development in critically ill patients protracts the artificial lung ventilation so that the phrenic nerves neuropathy may be the cause of complicated weaning. According to the prospective studies the authors ${ }^{7,9}$ suggested that hospital mortality rate increased in patients with neuromuscular disease who had artificial lung ventilation for more than 7 days. In the conducted research 48 patients with the signs of a severe sepsis were examined. The authors made the conclusion that the development of muscular weakness in the extremities (paralysis) along with the systemic inflammatory response and sepsis is a critically illness polyneuropathy. The development of polyneuropathy in patients affects the time of artificial lung ventilation, hospital stay and recovery time. ${ }^{7,9}$

The cause of polyneuropathy development could also be a protracted mechanical lung ventilation, vitamin deficiency, bacterial endotoxins, coagulopathy, the use of aminoglycosides (gentamicin), corticosteroids therapy and neuromuscular blocking agents, that are widely used in an intensive care medicine. ${ }^{10-14}$ Polyneuropathy has also been developed after acute respiratory distress syndrome, acute hypotonia episodes, injuries with no signs of sepsis or multiple organ failure. ${ }^{15,16} \mathrm{~A}$ matter of principle is to choose the treatment and prevention approach of polyneuropathy in patients undergone cardiosurgical interventions.

There is no specific management of polyneuropathy in critically ill patients nowadays. Everything is directed at preventive services. Prevention of polyneuropathy development in critically ill patients includes: sepsis and multiple organ failure treatment, ${ }^{17}$ tight glycemic control by insulin ranging from 4,6 to $6,1 \mathrm{mmol} / \mathrm{L} ;{ }^{8}$ early rehabilitation along with the physiotherapy that provides a faster recovery ${ }^{15,19-24}$ and improves artificial lung ventilation time as well as staying in an intensive care unit, ${ }^{25-31}$ it also ameliorates neuromuscular function and reduces disability:22,23 electrical muscle stimulation of extremities (every day sessions about $60 \mathrm{~min}$ long). ${ }^{32-35}$

Thus on the basis of comparative, correlation and factor analyses we can state that there are no preoperative or intraoperative predictors of polyneuropathy development in patients undergone cardiac surgeries. The polyneuropathy development is a result of postoperative sepsis, multiple organ failure, pneumonia, myocardial infarction, pleurisy that require a longer staying in an intensive care unit, protracted artificial lung ventilation, inotropic support and drug sedation as well as prolonged antibiotic therapy. Nowadays prevention and treatment of multiple organ failure, systematic inflammatory response, sepsis are the only and most essential methods of controlling polyneuropathy in patients undergone cardio-surgical interventions. Exclusion or careful use of corticosteroids, neuromuscular blocking agents along with an early rehabilitation and physiotherapy are critical to patient's recovery.

\section{Conclusion}

Comorbidity background, types of heart surgery, the technique of surgical intervention and the specifics of anesthetic support are not the cause of polyneuropathy in patients undergoing heart surgery. Patients with polyneuropathy suffered from sepsis, multiple organ failure, pneumonia, myocardial infarction more often. These patients stayed in the intensive care unit for a longer time. They needed inotropic support, drug sedation, mechanical ventilation and prolonged antibiotic therapy more often. Therefore, the developed polyneuropathy in patients undergone cardio-surgical interventions is critical illness polyneuropathy.

\section{Acknowledgments}

None.

\section{Conflicts of interest}

The authors declare no conflicts of interest

\section{Funding}

None.

\section{References}

1. Hensley FA, Martin DE, GP Grevle. Practical cardioanesthesiology. 3rd edn, USA, 2008. pp. 1104.

2. Shevchenko YL, Gorokhovatsky YI, Azizov OA, et al. Systemic inflammatory response in extreme surgical aggression. 2009.

3. Thiele RI, Jakob H, Hund E, et al. Critical illness polyneuropathy:a new iatrogenically induced syndrome after cardiac surgery? Eur $J$ Cardiothorac Surg. 1997;12(6):826-835.

4. Chen CA, Chang FY. Acute quadriplegia complicating critical illness polyneuropathy in a patient with infective endocarditis:a case report. $J$ Infect. 2005;50(2):153-157.

5. Markewitz A, Faist E, Lang S, et al. Successful restoration of cell-mediated immune response after cardiopulmonary bypass by immunomodulation. J Thorac Cardiovasc Surg. 1993;105(1):15-24.

6. Charles F Bolton. The Polyneuropathy of Critical Illness. Journal of Intensive Care Medicine. 1993. pp. 119-128.

7. Garnacho-Montero J, Amaya-Villar R, Garcia-Garmendia JL, et al. Effect of critical illness polyneuropathy on the withdrawal from mechanical ventilation and the length of stay in septic patients. Crit Care Med. 2005;33(2):349-354

8. De Jonghe B, Bastuji-Garin S, Sharshar T, et al. Does ICU acquired paresis lengthen weaning from mechanical ventilation? Intens Care Med. 2004;30(6):1117-1121

9. Khan J, Harrison TB, Rich MM, et al. Early development of critical illness myopathy and neuropathy in patients with severe sepsis. Neurology. 2006;67(8):1421-1425.

10. Bolton CF, Gilbert JJ, Hahn AF, et al. Polyneuropathy in critically ill patients. J Neurol Neurosurg Psychiatry. 1984;47(11):1223-1231.

11. Bolton CF, Laverty DA, Brown JD, et al. Critically ill polyneuropathy:electrophysiological studies and differentiation from Guillain-Barré syndrome. J Neurol Neurosurg Psychiatry. 1986;49(5):563-573.

12. Annane D, Bellissant E, Bollaert PE, et al. Corticosterpids for treating severe sepsis and septic shock. Cochrane Database Syst Rev. 2004;(1):CD002243

13. Marissa Keaveney. Critical Illness Polyneuropathy in Adults After Cardiac Surgery: a Case Study. Am J Crit Care. 2004;13(5):421-424.

14. Bolton C, Young B, Zochodne D. The neurological complications of sepsis. Ann Neurol. 1993;33(1):94-100.

15. Latronico N, Bertolini G, Guarneri B, etal. Simplified electrophysiological evaluation of peripheral nerves in critically ill patients:the Italian multicentre CRIMYNE study. Crit Care. 2007;11(1):R11.

16. Cankayali I, Dogan YH, Solak I, et al. Neuromuscular deterioration in the early stage of sepsis in rats. Crit Care. 2007;11(1):R1. 
17. Rudiger A, Singer M. Mechanisms of sepsis-induced cardiac dysfunction. Crit Care Med. 2007;35(6):1599-1608.

18. Van den Berghe G, Schoonheydt K, Becx P, et al. Insulin therapy protects the central and peripheral nervous system of intensive care patients. Neurology. 2005;64(8):1348-1353.

19. Hermans G, Wilmer A, Meersseman W, et al. Impact of intensive insulin therapy on neuromuscular complications and ventilator dependency in the medical intensive care unit. Am $J$ Resp Crit Care Med. 2007; 175(5):480-489.

20. Rochester CL. Rehabilitation in the intensive care unit. Semin Respir and Crit Care Med. 2009;30(6):656-669.

21. Zink W, Kollmar R, Schwab S. Critical illness polyneuropathy and myopathy in the intensive care unit. Nat Rev Neurol. 2009;5(7):372-379.

22. Silva A, Maynard K, Cruz M. Effect of motor physical therapy in critically ill patients. Rev Bras Ter Intensiva. 2010;22(1):85-91.

23. Perme C, Chadrashekhar R. Early mobility and walking program for patients in intensive care units:creating a standard of care. Am Crit Care. 2009;18(3):212-221.

24. Pereira Da Silva A, Maynard K, Rodrigues Da Cruz M. Effects of motor physical therapy in critically ill patients. Rev Bras Ter Intensiva. 2010;22(1):85-91.

25. Needham DM. Mobilizing patients in the intensive care unit:improving neuromuscular weakness and physical function. JAMA. 2008;300(14):1685-1690.
26. Schweickert WD, Pohlman MC, Pohlman AS, et al. Early physical and occupational therapy in mechanically ventilated, critically ill patients:a randomised controlled trial. Lancet. 2009;373(9678):1874-1882.

27. Jones A. Evidence based physiotherapy in intensive care. Hong Kong Physioth J. 2000;18(2):47-52.

28. Denhy L, Berney S. Physiotherapy in intensive care unit. Phys Ther Rev. 2006;11(1):49-56.

29. Stiller K. Physiotherapy in Intensive Care: Towards an Evidence-Based Practice. Chest. 2000;118(6):1801-1813.

30. Milbrandt EB. One small step for man. Crit Care Med. 2007;35:311312.

31. Bailey P, Thomsen GE, Sphuhler VJ, et al. Early activity is feasilble and safe in respiratory failure patients. Crit Care Med. 2007;35(1):139-145.

32. Karatzanos E, Gerovasili V, Zervakis D, et al. Electrical muscle stimulation: an effective form of exercise and early mobilization to preserve muscle strength in critically ill patients. Crit Care Res Prac. 2012;(2012):432752.

33. Routsi C, Gerovasili V, Vasileiadis I, et al. Electrical muscle stimulation prevents critical illness polyneuromyopathy:a randomized parallel intervention trial. Crit Care. 2010;14(2):R74

34. Pattanshetty RB, Gaude GS. Critical illness myopathy and polyneuropathy - A challenge for physiotherapists in the intensive care units. Indian J Crit Care Med. 2011;15(2):78-81. 